Article

\title{
Controllable Acid/Base Propriety of Sulfate Modified Mixed Metal Oxide Derived from Hydrotalcite for Synthesis of Propylene Carbonate
}

\author{
Zhongxie Ding ${ }^{1, \dagger}$, Wenlong $\mathrm{Xu}^{2,+}{ }^{\dagger}$, Xingguang Zhang ${ }^{3}$, Zhen Liu ${ }^{1}$, Jiecan Shen ${ }^{1}$, \\ Jinhua Liang ${ }^{2, *}$, Min Jiang ${ }^{2}$ and Xiaoqian Ren ${ }^{1, *}$ \\ 1 College of Chemical Engineering, Nanjing Tech University, Jiangsu 211816, Nanjing, China; \\ dxx@njtech.edu.cn (Z.D.); zhenliu311@163.com (Z.L.); jcshen311@163.com (J.S.) \\ 2 State Key Labboratory of Materials-oriented Chemical Engineering, Nanjing Tech University, Jiangsu 211816, \\ Nanjing, China; constantinos@njtech.edu.cn (W.X.); jiangmin@njtech.edu.cn (M.J.) \\ 3 College of Chemical Engineering, Nanjing Forestry University, Jiangsu 210037, Nanjing, China; \\ x.g.zhang@njfu.edu.cn \\ * Correspondence: jhliang@njtech.edu.cn (J.L.); xqren@njtech.edu.cn (X.R.); \\ Tel.: +86-137-7059-8601 (J.L.); +86-139-5164-5412 (X.R.) \\ + These two authors contribute equally in composing it.
}

Received: 27 March 2019; Accepted: 15 May 2019; Published: 21 May 2019

\begin{abstract}
Ammonium persulfate modified mixed metal oxide derived from hydrotalcite with tunable acid/base properties can be prepared via thermal decomposition of Mg-Al hydrotalcite-type precursors and ammonium persulfate. By controlling the ammonium persulfate content, these sulphur mutated samples, denoted as SMgAlO-y $(\mathrm{y}=1 ; 3 ; 5 ; 7)$, were investigated in this research. The resulted materials were characterized by XRD, SEM, FT-IR spectra, Py-IR spectra, XPS, Hammett indicator, $\mathrm{CO}_{2}$-TPD, as well as $\mathrm{NH}_{3}$-TPD. Furthermore, the acid-base property of the sample surface was determined by inverse gas chromatography measurements (IGC). Among all the obtained outcomes, the target $\mathrm{SMgAlO}-5$ demonstrated the maximal $\mathrm{K}_{\mathrm{a}} / \mathrm{K}_{\mathrm{b}}$ value, and it presented the highest activity as a catalyst in the synthesis of propylene carbonate (PC) through 1,2-propylene glycol and urea, giving the yield of $97.2 \%$ at the optimized reaction condition, which indicated that the PC yield counted on the synergic effect of the acidity and basicity on catalysts.
\end{abstract}

Keywords: Mg-Al metal oxide; ammonium persulfate; propylene carbonate; urea alcoholysis; cooperative effect

\section{Introduction}

Propylene carbonate (PC) is a typical inert organic solvent and is widely applied to synthesize dimethyl carbonate, diethyl carbonate, and macromolecular polymers [1-6]. The synthesis of PC from urea and propylene glycol (PG) presents the advantages of economical and abundant raw materials, mild reaction conditions, and high safety [7-9]. Particularly, propylene glycol, used as raw material in this method, is a byproduct in the transesterification process for the synthesis of dimethyl carbonate [10-12]. In this regard, such synthetic strategy conforms to the concept of environmentally-friendly process.

A series of attempts have been reported in literature, it is an intriguing strategy to select single metal oxide materials, such as $\mathrm{MgO}$ [13], $\mathrm{CaO}$ [14], and $\mathrm{ZnO}[15,16]$, and the similar type samples, as a catalyst in the catalytic synthesis of PC with a desirable yield. However, the requirement of reaction conditions is extremely harsh when these materials were applied as catalysts in the synthesis process, which constricted by thermodynamic equilibrium, and an additional vacuum condition is obligatory [17]. Moreover, the reaction may bring $\gamma$-valerolactone into the yield mixture through a 
side-reaction procedure [13]. Alternatively, the introduction of metal oxides with perovskite structures by ion exchange as catalysts can also be evangel in catalytic synthesis of PC, while the recyclability is unsatisfied due to the easily leaching of active centers while, in the application of bimetallic oxide structures, arouse an unexpected triumph. Zn-Al oxides with acid/base sites revealed an excellent catalytic performance for PC synthesis, and the yield of PC could reach $87.4 \%$ under a mild reaction environment with optimal recycling turns [9]. In this reaction, the strong alkaline sites of the catalyst can adsorb the reactant alcohol to form alkoxide ions [18-20] while the acid sites can interact with alkoxide ions to stabilize them, which strengthened the reaction activity [21,22].

Encouraged by the preceding achievements, herein, we report the synthesis of PC from 1,2-propylene glycol (PG) and urea by constructing the mixed metal oxide derived from hydrotalcite catalysts with controllable acid/base properties [23-26]. The catalysts were prepared from the ammonium persulfate modification of MgAl-hydrotalcites [27]. Different amounts of ammonium persulfate were introduced during the modification process. A series of catalysts with different acidity and basicity were prepared and fully characterized in this investigation. The results revealed that the introduction of sulfur significantly affected the acidity and alkalinity of the oxide surface [28-30]. However, different from the same reaction catalyzed by fluorinated $\mathrm{MgAlO}(\mathrm{MgAlO}-\mathrm{F})$ under high pressure [31], the $\mathrm{MgAl}$ bilayer oxide modified by sulfate could promote the reaction more efficiently and can operate with mild conditions. More interestingly, the amount of additive sulfur could disturb the self-assembling property in the preparation of mixed metal oxide derived from hydrotalcite could improve the porosity and specific surface area of the obtained sample; hence, it is reasonable to believe that this will also affect the acid/base properties of the catalyst surface. These catalysts effectively improved the conversion of $\mathrm{PG}$ and urea to PC and the one with a high $\mathrm{K}_{\mathrm{a}} / \mathrm{K}_{\mathrm{b}}$ ratio exhibited the highest activity. A conceivable mechanism, in which urea and PG were simultaneously activated on sulfate-modified $\mathrm{MgO} / \mathrm{Al}_{2} \mathrm{O}_{3}$ is proposed on the basis of the literature and experimental results. The findings in this study and the approach to catalyst development based on materials chemistry could open significant avenues to practical applications.

\section{Results and Discussion}

\subsection{Characterization of Mixed Metal Oxide Derived from Hydrotalcite}

\subsubsection{Mophologic Structure}

Powder XRD analysis was performed in Figure 1a. The two sharp peaks at approximately $42.8^{\circ}$ [200] and 62.2 $2^{\circ}$ [220] correspond to the typical diffraction peaks of $\mathrm{MgO}$ and $\mathrm{MgAl}_{2} \mathrm{O}_{4}$ [32]. After modified by ammonium persulfate, no significant variation was observed in the XRD patterns, revealing the well-preservation of the crystal structures and excluding the phase transfer during the impregnation and calcination process [33]. The sharp peaks of the XRD results exhibited a high crystallinity after the synthesis of these oxide materials. The catalyst morphology can be directly elucidated through SEM images of MgAlO and SMgAlO-y, which are presented in Figure $1 \mathrm{~b}, \mathrm{c}$ and Figure S1 (Supporting information). All the samples were composed of random aggregation of sheet primary particles with the similar petal-like appearance. With the increase of sulfur content, the fragmentary degree of the obtained mixed metal oxide derived from hydrotalcite improved, and a very small Mg-Al fragment appeared frequently, as shown in the SEM images. It is reasonable to assume the addition of sulfur influences the crystals formation or deeply the self-assemblage of the raw species (Figure S1a,c). More detailed characterization would uncover the interesting appearance shown in the morphologic characterization. 
a)
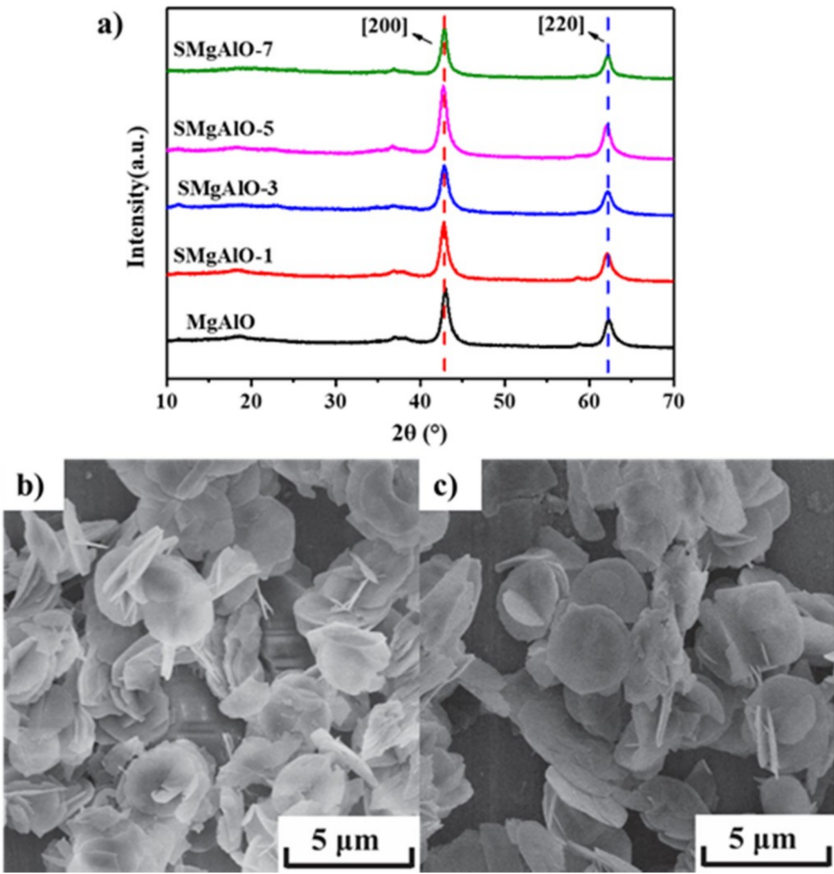

Figure 1. Crystal and morphologic structure of $\mathrm{MgAlO}$ and SMgAlO-y:XRD patterns (a); and SEM images of $\mathrm{MgAlO}$ (b), and $\mathrm{SMgAlO}-5$ (c).

\subsubsection{FT-IR Spectra}

With the change in sample morphologic features as described above, it is obvious for researchers to consider the variation of chemical bond-formation in the resulted materials. The usage of FT-IR could disclose the basic information of chemical bonds. The FT-IR spectra of MgAlO and SMgAlO-y are presented in Figure 2. FT-IR spectra presented that all catalysts exhibited a broad band between 3750 and $2750 \mathrm{~cm}^{-1}$ (centered at $3504 \mathrm{~cm}^{-1}$ ), demonstrating the presence of hydrogen-bonded perturbed hydroxyl groups, such as $\mathrm{Al}-\mathrm{OH}$ and adsorbed $\mathrm{H}_{2} \mathrm{O}$ (stretching vibration). They also displayed another strong absorption band centered at $1647 \mathrm{~cm}^{-1}$, which is assigned to the bending vibration of adsorbed $\mathrm{H}_{2} \mathrm{O}$ [34]. The absorption band at $852 \mathrm{~cm}^{-1}$ and $600 \mathrm{~cm}^{-1}$ are attributed to the vibrations of Al-O and $\mathrm{Mg}-\mathrm{O}$, and the subject of the transmittance peaks in all the samples can almost keep consistent, this could match the XRD results. However, there is a peak shift observed in the samples of SMgAlO-y with a significant peak at $1113 \mathrm{~cm}^{-1}$ in Figure $2 \mathrm{~b}$. It could correspond to the asymmetric stretching vibration of $\mathrm{S}=\mathrm{O}$ according to the literature, and this exhibited that sulfur species have been successfully introduced on the catalytic surface [35]. The effect of modification caused by the addition of sulfur becomes increasingly clear.

a)

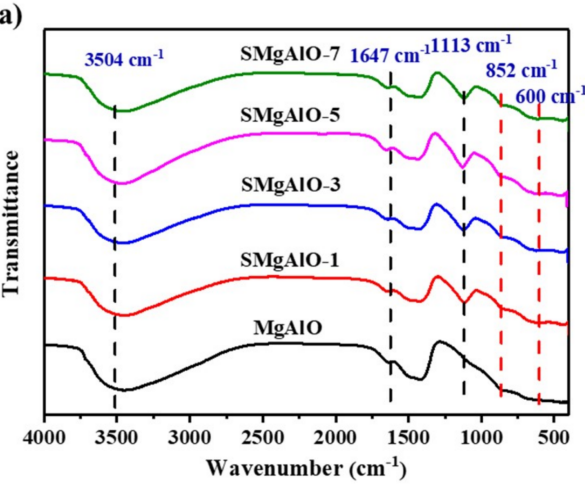

b)

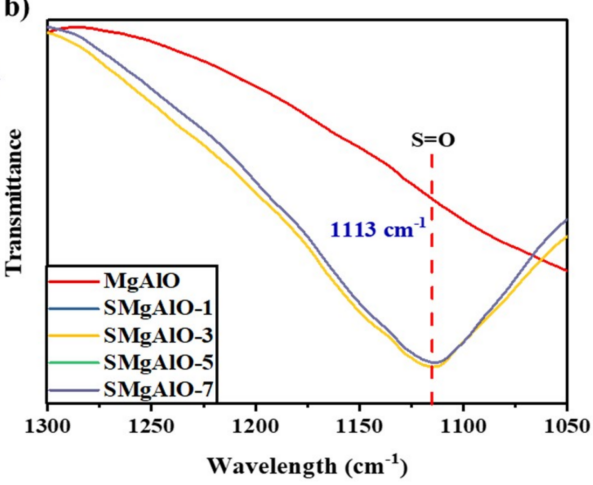

Figure 2. FT-IR spectra of $\mathrm{MgAlO}$ and SMgAlO-y (a), and the indicated enlarged part from $1050-1300 \mathrm{~cm}^{-1}(\mathbf{b})$. 


\subsubsection{Textural and Composition Properties}

Table 1 shows the textural and composition properties of the $\mathrm{MgAlO}$ and $\mathrm{SMgAlO}-\mathrm{y}$ series. Herein, the sulfur weight percentage of the samples were detected by EA, and the metal species were measured by ICP-OES. After modification, the original metal ratio did not change with the increase of sulfur species. However, it can be noticeably perceived that the real sulfur amount is far less than the inputs (nominal loading). This may be accounted for the detainment of sample porosity environment. Concerning for the porosity as resulted, the $\mathrm{N}_{2}$ adsorption characterization was carried out in our work (Figure S2). The $\mathrm{N}_{2}$ adsorption volumes of all samples are less than $100 \mathrm{~m}^{2} / \mathrm{g}$ based on the Brunauer-Emmett-Teller (BET) method. After modified with ammonium persulfate, SMgAlO-y series demonstrated larger surface area and pore volume than the original sample. Intriguingly, with the upsurge of sulfur additive, the caused resultant specific surface area and pore volume show a volcanic trend. It increased from $75.5 \mathrm{~m}^{2} / \mathrm{g}$ in the proto to the maximum of $101.4 \mathrm{~m}^{2} / \mathrm{g}$ at $\mathrm{y}=5$, and then declined to $90.6 \mathrm{~m}^{2} / \mathrm{g}$ after the input amount was enhanced to $7 \mathrm{wt} \%$. The similar phenomenon has been also reported in the iron-manganese doped sulfated zirconia in literature [35,36]. This tendency may be raised from the synergic effect of sulfur and self-assembling of the as prepared mixed metal oxide derived from hydrotalcite. This subsequent decline can suggest some structural collapse for the high loading, or some other inorganic content such as amorphous alumina sulfate and magnesium sulfate formed in the primitive structure [36].

Table 1. Textural properties of the mixed metal oxide derived from hydrotalcite series with different sulfur contents.

\begin{tabular}{|c|c|c|c|c|}
\hline \multirow[t]{2}{*}{ Samples } & \multirow{2}{*}{$\begin{array}{l}\text { Sulfur Content } \\
\quad(w t \%)^{a}\end{array}$} & ICP & \multirow{2}{*}{$\begin{array}{l}S_{B E T} b \\
\left(\mathrm{~m}^{2} / g\right)\end{array}$} & \multirow{2}{*}{$\begin{array}{c}\mathrm{V}_{\mathrm{T}}^{\mathrm{c}} \\
\left(\mathrm{cm}^{3} / \mathrm{g}\right)\end{array}$} \\
\hline & & Mg: Al & & \\
\hline $\mathrm{MgAlO}$ & - & $4.01: 1$ & 75.5 & 0.26 \\
\hline SMgAlO-1 & 0.37 & 3.93: 1 & 81.5 & 0.25 \\
\hline SMgAlO-3 & 1.21 & 4.01: 1 & 89.8 & 0.28 \\
\hline SMgAlO-5 & 2.24 & 3.96: 1 & 101.4 & 0.31 \\
\hline SMgAlO-7 & 3.19 & 3.98: 1 & 90.6 & 0.22 \\
\hline
\end{tabular}

${ }^{\mathrm{a}}$ detected by an elemental analysis instrument; ${ }^{\mathrm{b}}$ BET surface area; ${ }^{\mathrm{c}}$ total pore volume.

\subsubsection{XPS Characterization}

To further explore the effect of sulfur addition on the catalyst surface, especially the insights into the surface characteristics, XPS analysis was applied to identify the oxidation state of $\mathrm{C}, \mathrm{S}, \mathrm{Al}$, and $\mathrm{Mg}$ on the materials (Figure 3). The binding energy (BE) values of Al $2 p$ (74.6-77.1 eV) (Figure 3b) and Mg $2 p(50.0-52.7 \mathrm{eV}$ ) (Figure 3c) are characterized and showed that the intensity of both elements declined drastically with the addition of sulfur amount. The signal of S $2 p(169.2 \mathrm{eV})$ enhanced gradually after the input additive amount which ranged from 1-7 (Figure 3d), suggesting the existence of $\mathrm{S}^{6+}\left(\mathrm{SO}_{4}{ }^{2-}\right)$ rather than the simple adsorption of sulfur molecules [36]. However, an intriguing observation has been obtained in the XPS results which can provide more information for the description of sulfur modification effect. From the previous depiction with the textural study, we are interested in the distinctive volcano curve after the rise of sulfur. It may be manifested as structural collapse occurred in the $\mathrm{Mg}$-Al layer dioxide framework especially in the process of self-assembling which could be common in the report of defective metal organic frameworks (MOFs) [37]. Thus, the further addition of sulfate (from 5-7) could reduce the intensity of S $2 p$ signal in the XPS figure (Figure 3d). Fortunately, revealed by Figure $3 b$, the signal of $\mathrm{Al} 2 p \mathrm{BE}$ in $77.1 \mathrm{eV}$ can be more and more distinct as sulfur addition ranged from 1-5; this signal is practically identical to the spectra that have been reported as $\mathrm{Al}_{2}\left(\mathrm{SO}_{4}\right)_{3}$ [38-40]; Meanwhile, the signals of $\mathrm{Al} 2 p \mathrm{BE}$ in $74.6 \mathrm{eV}\left(\mathrm{Al}_{2} \mathrm{O}_{3}\right)$ and $75.4 \mathrm{eV}\left(\mathrm{Al}(\mathrm{OH})_{3}\right)$ decline gradually at the same time. Moreover, the same phenomena can be observed in the result of magnesium (Figure 3c), the signals that appeared in $\mathrm{BE}$ of $50.0 \mathrm{eV}, 50.9 \mathrm{eV}$ and $52.7 \mathrm{eV}$ are clear 
evidence of the presence of $\mathrm{MgO}, \mathrm{Mg}(\mathrm{OH})_{2}$, and $\mathrm{MgSO}_{4}$ as reported in literature [41,42]. It can also be explained as the syngeneic effect of sulfur addition and sulfate can form with the introduction of sulfur species. In addition, as S increased to 7 , both $\mathrm{Al} 2 p$ and $\mathrm{Mg} 2 p$ XPS results altered. Although the oxides signal continues to decrease, the signals of both $\mathrm{Al} 2 p$ and $\mathrm{Mg} 2 p$ shift gradually from sulfate to hydroxide, the signals of 77.1 and $52.7 \mathrm{eV}$ are weakened while 75.4 and $50.9 \mathrm{eV}$ were enhanced after the modification. This could be strong evidence that the frameworks tend to change. Combined with the volcanic tendency of textural properties, it is reasonable to conclude that the framework collapsed after the doping amount reached an extremum [35]. In summary, these results demonstrate that $\mathrm{MgAlO}$ was successfully modified by the ammonium persulfate.
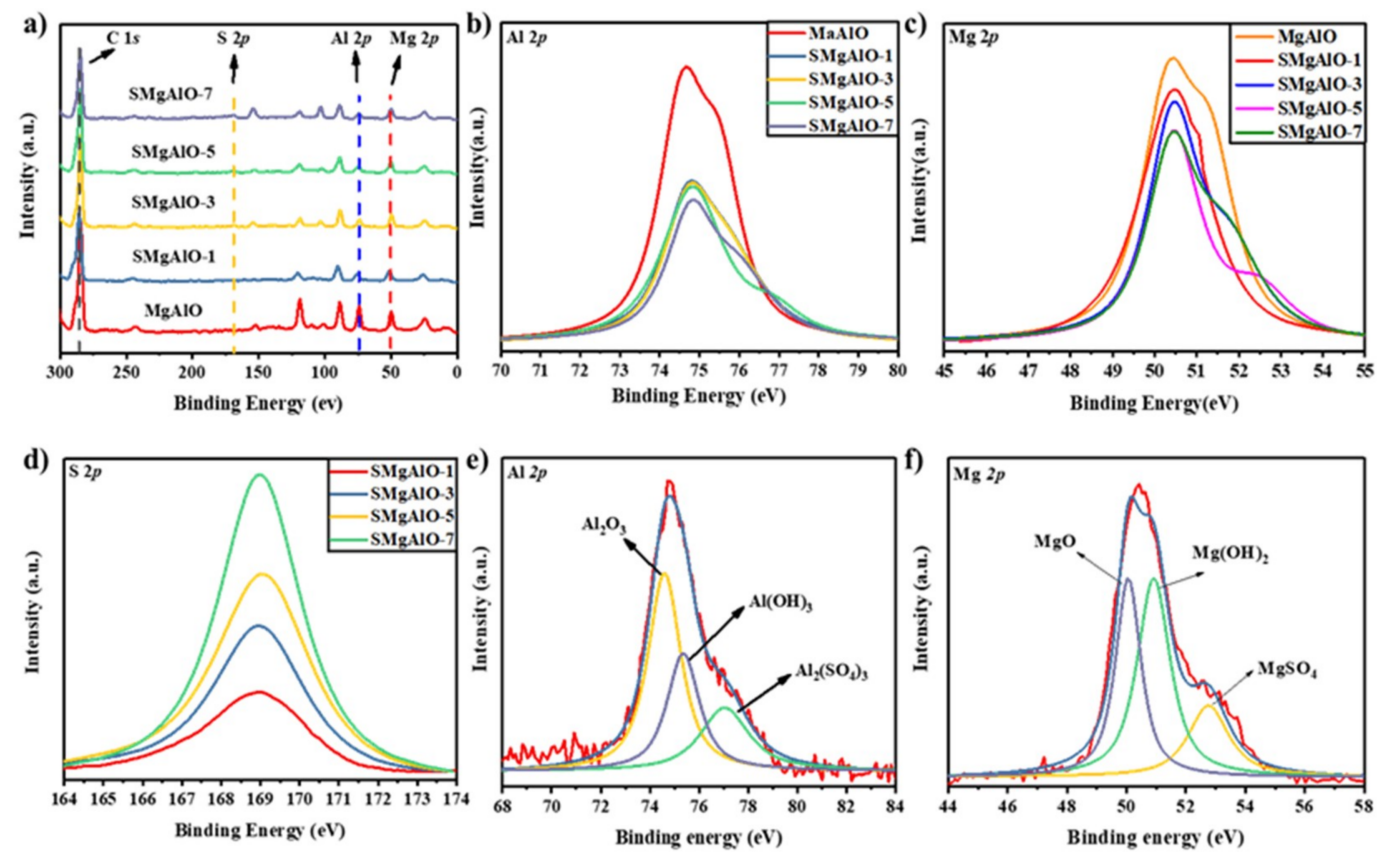

Figure 3. XPS spectra for full scan (a), $\mathrm{Al} 2 \mathrm{p}$ for SMgAlO (b), Mg 2p for SMgAlO (c), S 2p for SMgAlO (d), $2 \mathrm{p} \mathrm{Al}$ for SMgAlO-5 (e), and Mg 2p for SMgAlO-5 (f).

\subsection{Acid-Base Site Characterization}

Alumina oxides contain tremendous acid sites due to the existence of empty orbitals, which can act as a Lewis acid [43]. In order to determine the acid-base properties of the as prepared samples, $\mathrm{NH}_{3}$-TPD (acid sites) and $\mathrm{CO}_{2}$-TPD (base sites) were chosen to study in this work. The $\mathrm{NH}_{3}$-TPD results of MgAlO and SMgAlO-y series are shown in Figure 4a and Table 2. MgAlO and SMgAlO-1 exhibited the desorbed peaks of weak and strong acidic sites at 459 and $750 \mathrm{~K}$, respectively. Moreover, SMgAlO-3, SMgAlO-5, and SMgAlO-7 exhibited two peaks at higher temperatures (484 and $785 \mathrm{~K}$ ). The amount of strong acid of $\mathrm{SMgAlO}-1$ is larger than those of $\mathrm{MgAlO}$. This phenomenon indicates that the strong acid sites are dominated over $\mathrm{SMgAlO}-\mathrm{y}$ series. The highest total acid amount was achieved over SMgAlO-5, reflecting that this sample has the largest amount of acid sites. $\mathrm{CO}_{2}$-TPD results are presented in Figure $4 \mathrm{~b}$ and Table 2. $\mathrm{MgAlO}$ demonstrated two $\mathrm{CO}_{2}$ desorption peaks at 507 and $714 \mathrm{~K}$, attributable to the weak and strong basic sites, respectively. The $\mathrm{CO}_{2}$ desorption peaks of SMgAlO-y shifted to lower temperatures (from 493 and $692 \mathrm{~K}$ to 464 and $676 \mathrm{~K}$ ), in line with the decline of the basicity. The total basicity amount of $\mathrm{MgAlO}$ is the largest among series of SMgAlO-y. 
a)

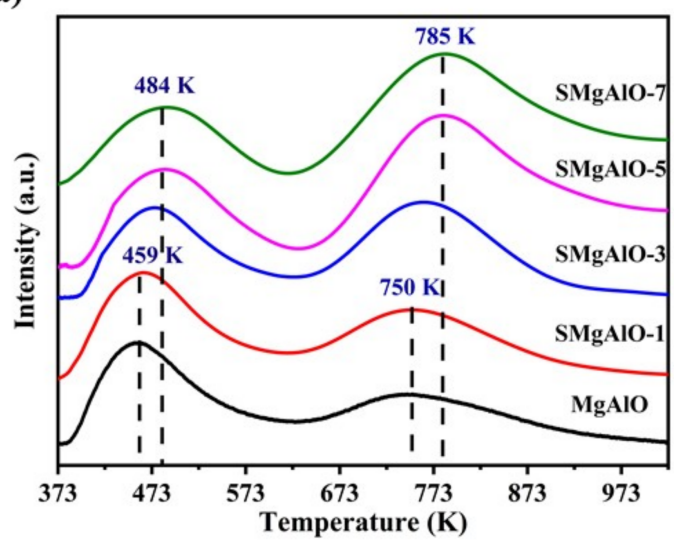

b)

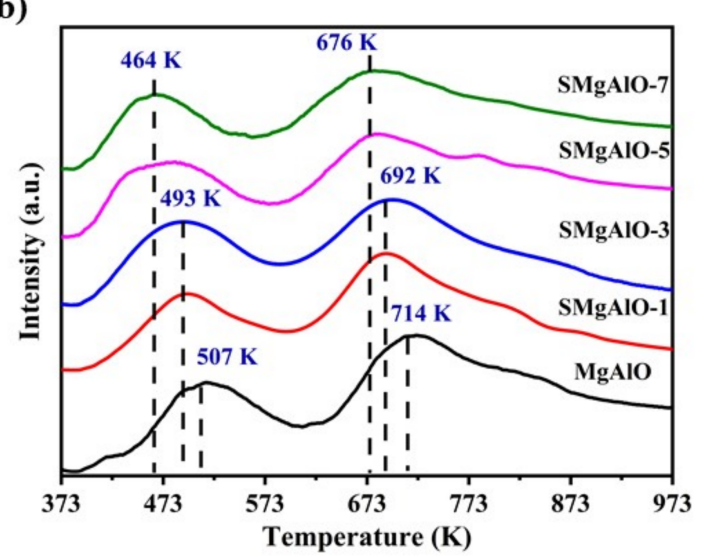

Figure 4. $\mathrm{NH}_{3}$-TPD curves of MgAlO and SMgAlO-y series (a); and $\mathrm{CO}_{2}$-TPD curves of MgAlO and SMgAlO-y series $(\mathbf{b})$.

Table 2. Acidity, and alkalinity of $\mathrm{MgAlO}$ and $\mathrm{SMgAlO}-\mathrm{y}$ series.

\begin{tabular}{|c|c|c|c|c|c|c|}
\hline Samples & \multicolumn{2}{|c|}{ Distribution of Acidic Sites } & $\begin{array}{c}\text { Total Acidic } \\
\text { Sites } / \mathrm{mmol}^{-1}{ }^{-1}\end{array}$ & \multicolumn{2}{|c|}{ Distribution of Alkaline Sites } & $\begin{array}{l}\text { Total Alkaline } \\
\text { Sites } / \mathrm{mmol}^{-1}{ }^{-1}\end{array}$ \\
\hline $\mathrm{MgAlO}$ & 0.096 & 0.026 & 0.122 & 0.435 & 0.527 & 0.962 \\
\hline SMgAlO-3 & 0.125 & 0.146 & 0.271 & 0.422 & 0.413 & 0.835 \\
\hline SMgAlO-5 & 0.143 & 0.215 & 0.358 & 0.403 & 0.388 & 0.791 \\
\hline SMgAlO-7 & 0.124 & 0.191 & 0.315 & 0.387 & 0.341 & 0.728 \\
\hline
\end{tabular}

$A_{w}$ : weak acidic sites; $A_{s}$ : strong acidic sites; $B_{w}$ : weak alkaline sites; $B_{s}$ : strong alkaline sites.

For further determining the detailed base strength of the obtained mixed metal oxide derived from hydrotalcite, the Hammett indicator method is applied here, in which phenolphthalein and 2,4,6-trinitroaniline were selected as the indicator to correspond to the weak base and the strong base, respectively. Table 3 presents the Hammett indicators results of $\mathrm{MgAlO}$ and $\mathrm{SMgAlO}-\mathrm{y}$ series. All the alkali number modified by ammonium persulfate elucidated a downward trend not only in the weak and but in the strong basis sites, which could decrease from 2.31 to $2.08 \mathrm{mmol} / \mathrm{g}$ under phenolphthalein $(\mathrm{H} \geq 9.3)$ and 0.45 to $0.24 \mathrm{mmol} / \mathrm{g}$ under 2,4,6-trinitroaniline $(\mathrm{H} \geq 12.2)$, respectively. The precipitous results match well with the observation in $\mathrm{CO}_{2}$-TPD profiles. Thus, with the growth of sulfur additives, the basic property would decline apparently.

Table 3. Hammett indicator.

\begin{tabular}{cccc}
\hline \multirow{2}{*}{ Catalyst } & \multicolumn{3}{c}{ Alkali Number/mmol.g $\mathbf{- 1}^{\mathbf{1}}$} \\
\cline { 2 - 4 } & phenolphthalein $\boldsymbol{H}_{-} \mathbf{z} \mathbf{9 . 3}$ & $\mathbf{2 , 4 , 6 - t r i n i t r o a n i l i n e ~} \mathbf{H}_{-} \mathbf{2} \mathbf{1 2 . 2}$ & Total \\
\hline MgAlO & 2.31 & 0.45 & 2.76 \\
SMgAlO-1 & 2.17 & 0.30 & 2.47 \\
SMgAlO-3 & 2.13 & 0.28 & 2.41 \\
SMgAlO-5 & 2.12 & 0.26 & 2.38 \\
SMgAlO-7 & 2.08 & 0.24 & 2.32 \\
\hline
\end{tabular}

To further determine the acid types (Brönsted or Lewis) in all the samples, Py-IR spectra were used in our work. Figure 5 shows the Py-IR spectra results of $\mathrm{MgAlO}$ and SMgAlO-y series. All the samples present a peak at $1427 \mathrm{~cm}^{-1}$ assignable to the pyridine bonded to the Lewis acidic sites. In terms of the area of the absorption peaks, the acid contents of the $\mathrm{SMgAlO}-\mathrm{y}$ were stronger than that of $\mathrm{MgAlO}$, and the peak, indicating the Lewis acid sites, could improve continuously along with the addition of ammonium persulfate. As a result of the strong electrons attraction property dedicated from two covalent bonds $\mathrm{S}=\mathrm{O}$, the center metal atoms lack electrons severely, thus, strong Lewis acidic sites are generated [27]. 


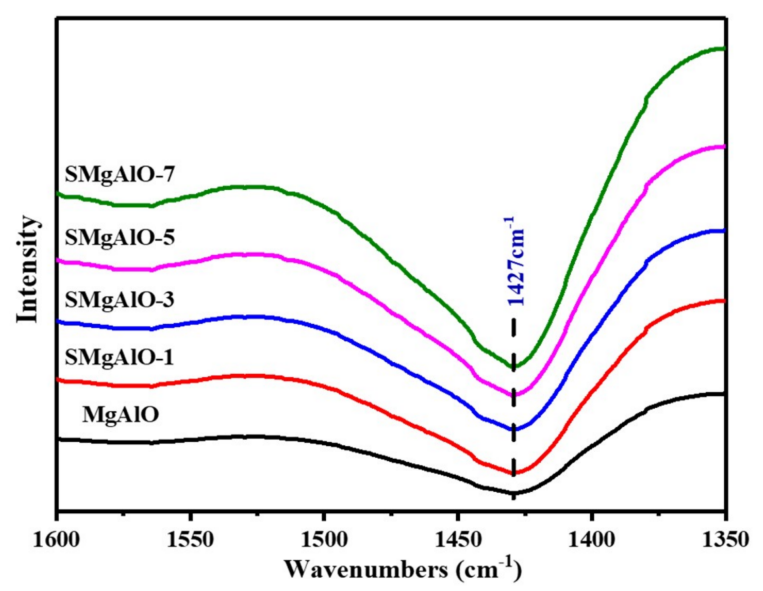

Figure 5. Py-IR analysis of $\mathrm{MgAlO}$ and $\mathrm{SMgAlO}-\mathrm{y}$.

Inverse gas chromatography (IGC) technology reflects the surface property parameters of the stationary phase by the equilibrium interaction of adsorption and separation between small organic molecules and the material to be tested. Therefore, it was frequently used to determine the surface basicity and acidity of mixed metal oxide derived from hydrotalcite. The results in Table 4 exhibited that $\mathrm{K}_{\mathrm{a}}$ values of SMgAlO-y were higher than that of $\mathrm{MgAlO}$, indicating that the modification of ammonium persulfate could improve the acidity of the surface of the material whereas, after modification, the $\mathrm{K}_{\mathrm{a}}$ values can also express a volcanic tendency as described in the BET adsorption, it rises from 0.098 (proto) to the maximum $0.179(y=5)$, where exhibits its largest acid sites, and then decline slightly to $0.172(\mathrm{y}=7)$ while $\mathrm{K}_{\mathrm{b}}$ values, indicators of the basic sites, of the primitive $\mathrm{MgAlO}$ were slightly higher than those after modification. The $\mathrm{K}_{\mathrm{b}}$ values of SMgAlO-y decreased along with the sulfur addition (from 0.681 to 0.649 ). Finally, all the $\mathrm{K}_{\mathrm{a}} / \mathrm{K}_{\mathrm{b}}$ acquired are less than 1, indicating that the material possesses a strong alkali but weak acidity. Moreover, remarkably, the $\mathrm{K}_{\mathrm{a}} / \mathrm{K}_{\mathrm{b}}$ value also exhibited a volcanic profile, which increases from 0.144 to 0.274 , then descends to 0.265 , indicating that the volcanic route of acidity variation in the mixed metal oxide derived from hydrotalcite. All these results were in perfect accordance with the results of TPD profiles and Hammett indicators obtained above, and it indicates that $\mathrm{SMgAlO}-5$ (sulfur input amount is $5 \%$ ) can be further treated as a potential acid-base catalyst for the synthesis of PC.

Table 4. Acid-base properties measured by inverse gas chromatography (IGC).

\begin{tabular}{cccccc}
\hline Sample & $\mathbf{K}_{\mathbf{a}}$ & $\mathbf{K}_{\mathbf{b}}$ & $\mathbf{K}_{\mathbf{a}}+\mathbf{K}_{\mathbf{b}}$ & $\mathbf{K}_{\mathbf{a}} / \mathbf{K}_{\mathbf{b}}$ & Yield of PC (\%) \\
\hline MgAlO & 0.098 & 0.681 & 0.779 & 0.144 & $83.4 \pm 0.4$ \\
SMgAlO-1 & 0.132 & 0.679 & 0.811 & 0.194 & $85.1 \pm 0.6$ \\
SMgAlO-3 & 0.156 & 0.659 & 0.815 & 0.237 & $90.5 \pm 0.2$ \\
SMgAlO-5 & 0.179 & 0.653 & 0.832 & 0.274 & $97.2 \pm 0.3$ \\
SMgAlO-7 & 0.172 & 0.649 & 0.821 & 0.265 & $96.3 \pm 0.2$ \\
\hline
\end{tabular}

Reaction condition: $\mathrm{n}_{(\mathrm{PG})} / \mathrm{n}_{\text {(urea) }}=3$; mass fraction of catalysts $=1 \%$; reaction time $=5 \mathrm{~h}$; reaction temperature $=$ $433 \mathrm{~K}$.

\subsection{PC Catalytic Synthesis}

\subsubsection{Catalytic Activity of the Synthesis of PC}

Lewis acid sites played an important role in various catalytic reactions [44]. As we have described above, the abundant Lewis acidic sites located on the surface of $\mathrm{Mg}$-Al layer dioxide could provide a platform to transfer the reactants PG and urea. The weak alkaline sites can induce the reaction into a balance to improve the selectivity of target PC [45]. In Table 4, we have carried out the synthesis of PC. When the $\mathrm{K}_{\mathrm{a}} / \mathrm{K}_{\mathrm{b}}$ shifts from 0.144 to 0.274 and then drops to 0.265 with the gradual increase of sulfur 
content, the yield of PC could range from $83.4-97.2 \%$ followed with falling to $96.3 \%$ under suitable conditions (marked in the label note of Table 4). This result revealed that (1) Mg-Al layer dioxides can be reasonable catalysts in the environmental-friendly synthesis of PC from PG and urea; and (2) the modified Lewis acid sites resulted from the increased sulfur species could efficiently and dominantly promote the reaction to the formation of the target PC. However, the collapse of $\mathrm{Mg}$-Al layer dioxide framework triggered by the excessive introduction of sulfur atom would turn it back. Among all the materials we obtained, the $\mathrm{SMgAlO}-5$ can be confirmed as the best catalyst candidate for the synthesis of PC.

To optimize the reaction conditions (Figure 6), the influence of reaction time on the yield has also been investigated, by varying the reaction time from 2.0 to $6.0 \mathrm{~h}$ (interval for $1.0 \mathrm{~h}$ ) at the same conditions of $1 \%$ of SMgAlO-5, mole ratio of PG to urea $\left(\mathrm{n}_{(\mathrm{PG})}: \mathrm{n}_{(\text {urea })}\right)=3: 1$ under $433 \mathrm{~K}$. In Figure 6a, the yield of PC increased from $32.0 \%$ to $97.2 \%$ with increasing time from 2.0 to $5.0 \mathrm{~h}$. After $5.0 \mathrm{~h}$, the result almost kept constant $(97.0 \%)$, owing to the depletion of reactant. The slightly decrease of yield can be illustrated as the formation of by-product.

a)

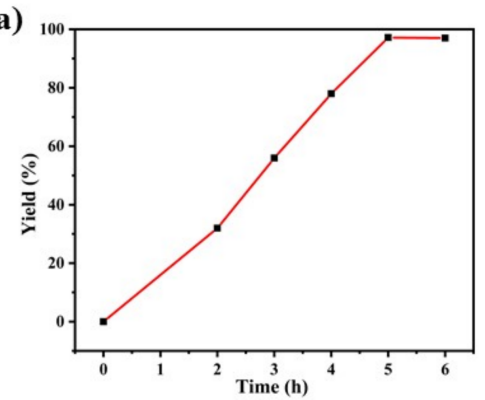

c)

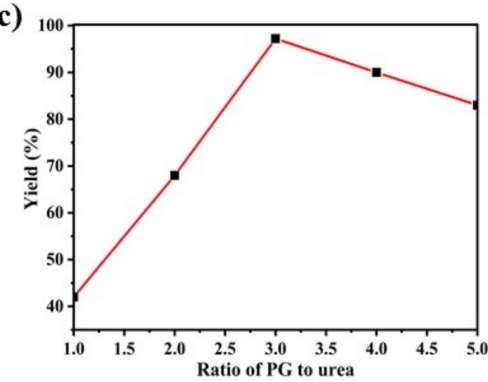

b)

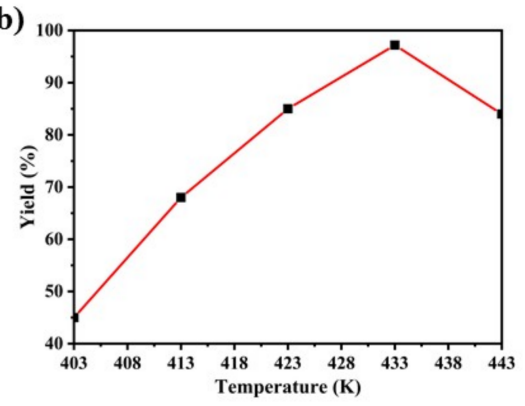

d)

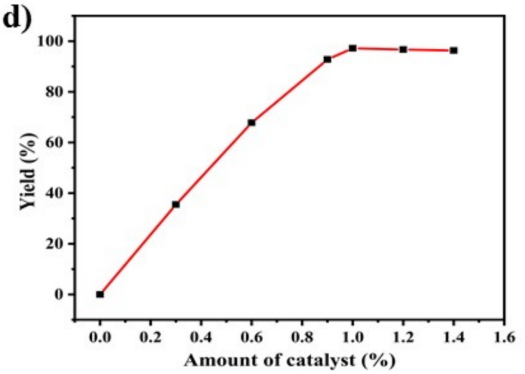

Figure 6. Process optimization research of the PC synthesis with effect of duration time (a), temperature (b), mole ratio of PG to urea $\left(\mathrm{n}_{(\mathrm{PG})}: \mathrm{n}_{(\text {urea })}\right)(\mathbf{c})$, and the amount of SMgAlO-5 catalyst in the reaction (d). Reaction conditions: SMgAlO-5 amount ( $1 \%$ for $(\mathbf{a}-\mathbf{c}))$, reaction time $(5 \mathrm{~h}$ for $(\mathbf{a}-\mathbf{c})), \mathrm{n}_{(\mathrm{PG}}: \mathrm{n}_{(\text {urea })}(3: 1$ for $(\mathbf{a}, \mathbf{b}, \mathbf{d}))$, and temperature $(433 \mathrm{~K}$ for $(\mathbf{b}-\mathbf{d}))$.

Figure $6 \mathrm{~b}$ exhibits the impact of temperature. The temperature increased from $403 \mathrm{~K}$ to $433 \mathrm{~K}$ resulted in the continuous enhancement of the activity, with PC yield changed from $45 \%$ to $97.2 \%$. However, higher temperature of $443 \mathrm{~K}$ caused a declined PC yield of $84 \%$, due to the decomposition of urea at high temperature. In addition, the investigation of the PG/urea molar ratio approved that at $\mathrm{n}_{(\mathrm{PG})}: \mathrm{n}_{\text {(urea) }}=3: 1$ the yield of PC can reach the maximum (Figure $6 \mathrm{c}$ ). The yield could drop rapidly with the further rise of PG/urea molar ratio prossimo. The yield of PC would fall to only $83 \%$ at $\mathrm{n}_{(\mathrm{PG})}: \mathrm{n}_{\text {(urea) }}=5: 1$. This can be explained by the urea dissolution property under PG environment. The low dissolution of urea in PG could detain the contraction efficiency to the surface of catalyst when the PG/urea molar ratio reaches a high level, which could reduce the transmission rate and further deteriorate the catalyst's activity [46]. Finally, the influence of catalyst mass has also been explored (Figure $6 \mathrm{~d}$ ), as we have described, after $5.0 \mathrm{~h}$, all the reactants have already totally consumed. The additional catalyst amount cannot improve the reaction to an endless margin. When the addition amount of SMgAlO-5 rise to more than $1 \%$, the yield of $\mathrm{PC}$ almost remain unchanged or present a 
slight decline (From $97.2 \pm 0.3 \%$ to $96.3 \pm 0.2 \%$, under $1.4 \%$ of SMgAlO-5). The catalyst can improve the positive and negative reaction simultaneously, the extra catalyst would accelerate the reverse reaction and it can be a reason for the slightly yield deterioration. In summary, the optimal reaction condition can be determined as followed: $\mathrm{n}_{(\mathrm{PG})} / \mathrm{n}_{\text {(urea) }}=3$; mass fraction of SMgAlO- 5 catalyst $=1 \%$; reaction time $=5 \mathrm{~h}$; reaction temperature $=433 \mathrm{~K}$; and the final yield of $\mathrm{PC}=97.2 \%$.

\subsubsection{Reusability of Catalyst}

Recovering the catalyst after the reaction is very important to the sustainable application of PC synthesis, which demands an excellent reusability and stability of the Mg-Al layer dioxide catalyst. Figure 7 gives the results of the five time reuse of the modified catalyst SMgAlO- 5 with little loss in catalytic activity and all the PC final yields are higher than $85 \%$. This result manifests that the $\mathrm{SMgAlO}-5$, as prepared, can be an outstanding candidate in the catalytic synthesis of PC.

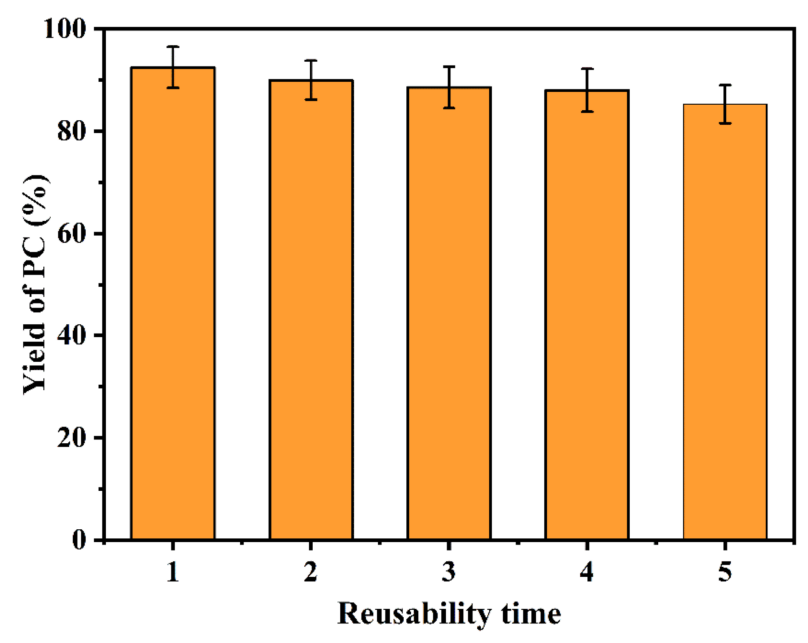

Figure 7. Recycling experiments of the benchmark reaction in the presence of the $\mathrm{SMgAlO}-5$ catalyst. Reaction condition: $\mathrm{n}_{(\mathrm{PG})} / \mathrm{n}_{\text {(urea) }}=3$; mass fraction of the catalyst $=1 \%$; reaction time $=5 \mathrm{~h}$; reaction temperature $=433 \mathrm{~K}$.

\subsection{Mechanism Discussion}

Given the relatively high activity and target selectivity with $\mathrm{SMgAlO}-5$ as catalyst in the synthesis of propylene carbonate through 1,2-propylene glycol and urea, this observed high yield of PC (97.2\%) under optimal reaction condition is quite intriguing. Compared to the currently used methods of producing PC over the: $\mathrm{MgCl}$ catalyst (yield $=96.5 \%$ ) [8], M/HAP catalyst (yield $=91.5 \%$ ) [35], and zinc acetate catalyst (yield $=78 \%$ ) [46], our approach exhibits an exceeding advantage amongst all these approaches. One possible explanation is due to the inductive effects of acid-base sites improved by the addition of sulfur species. The reaction accelerating effect through sulfur species have been reported in previous reports [47-49], and all the metal nodes on the $\mathrm{Mg}$-Al dioxides are improved and supplied as an excellent Lewis acid sites in reactions. Meanwhile, the original oxygen adjacent to the metal nodes could act as Lewis base sites because of the free outmost electrons on the oxygen orbital. The inductive effect could simultaneously upsurge the Lewis basicity of the dioxides [50]. In this work, a covalent $\mathrm{S}=\mathrm{O}$ bond could be observed through FT-IR on the samples after modified with sulfate introduction. After further characterization with an XPS test, it can be confirmed that the sulfur species exist in the form of $\mathrm{SO}_{4}{ }^{2-}$. With the increment of sulfur addition (less than $5 \%$ of sulfur addition), the intensity of sulfur could be more and more distinct, while the yield of PC with catalytic alcoholysis could increase from $83.4 \%$ to $97.2 \%$ step by step. However, the extra introduction of sulfur may cause the collapse of dioxide framework due to the interpenetration effect [35]. Therefore, the collapse lead to the hindrance of acid sides to deteriorate the catalyst activity and PC yield. This conjecture can be feasibly validated by the volcanic tendency of nitrogen adsorption results, the value of $\mathrm{K}_{\mathrm{a}} / \mathrm{K}_{\mathrm{b}}$ as well 
as the patently decline of PC yield (from the extreme $97.2 \%$ to $96.3 \%$ ) after the doping amount rise to $7 \%$. In summary, the proposed mechanism of catalytic alcoholysis reaction based on the modification of sulfur variation can be presented in Scheme 1. It is obvious to determine that after the enhancement of the Lewis acidity through metal nodes, these acidic centers and the basic centers supplied by the adjacent oxygen atoms of the catalyst surface concurrently attack the hydroxyl groups of the PG and the oxygen and nitrogen atoms in urea, followed by the form of alkoxide ions and positive charge in the $\alpha$-carbon atom formed in urea. Therefore, the target PC and the inevitable byproduct ammonia can produce under a nucleophilic reaction caused by the ions attack to the positive urea.

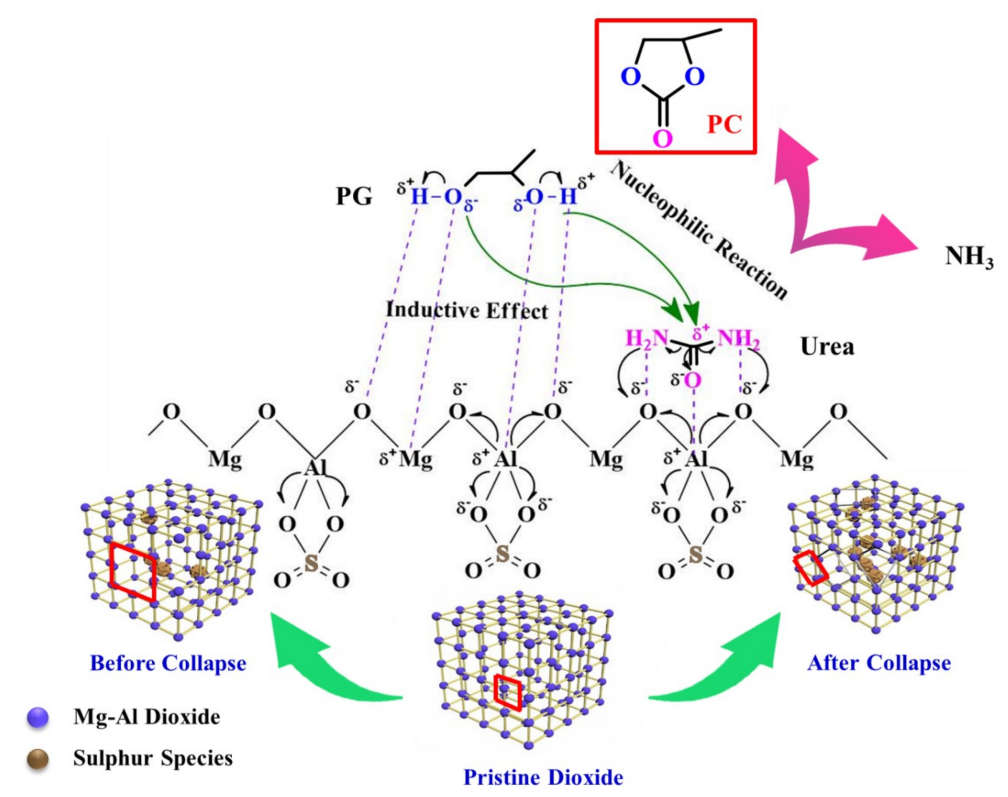

Scheme 1. Catalyst modification and catalytic reaction mechanism.

In order to confirm this volcanic variation tendency of catalytic reaction strongly depend on the acidity variation due to the change of dioxide framework. The most direct proof can be observed in Figure 8, which demonstrated the relationship between the value of $\mathrm{K}_{\mathrm{a}} / \mathrm{K}_{\mathrm{b}}$ and the yield of PC in the alcoholysis of PG and urea to PC. During the catalytic process, the target yield could gradually rise with the increase of the value of $\mathrm{K}_{\mathrm{a}} / \mathrm{K}_{\mathrm{b}}$. This monotonic increasing curve manifests that the unique catalytic property of the facile catalyst is merely decided by its structure.

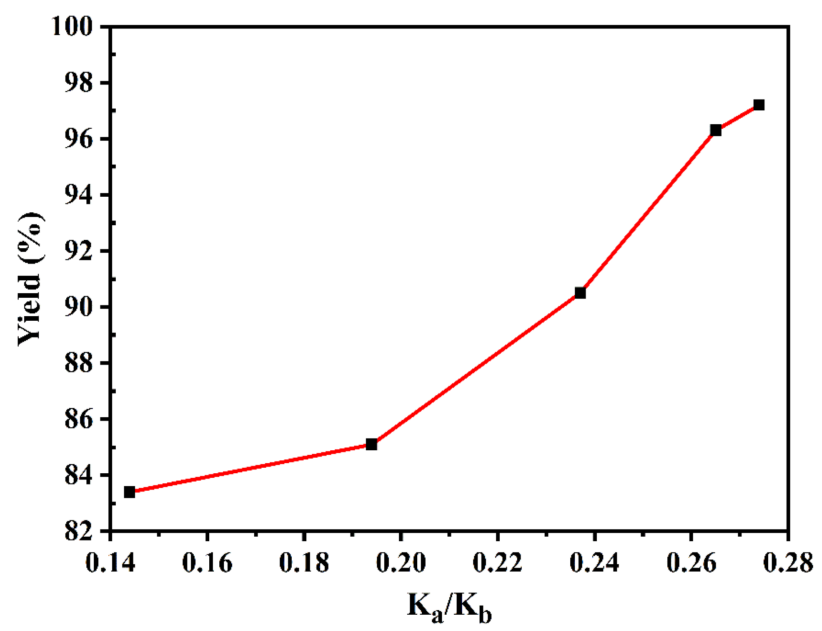

Figure 8. The relationship between the values of $\mathrm{K}_{\mathrm{a}} / \mathrm{K}_{\mathrm{b}}$ and the PC yield. Reaction condition: $\mathrm{n}_{(\mathrm{PG})} / \mathrm{n}_{\text {(urea) }}=3$; mass fraction of the catalyst $=1 \%$; reaction time $=5 \mathrm{~h}$; reaction temperature $=433 \mathrm{~K}$. 


\section{Materials and Methods}

\subsection{Catalyst Preparation}

$\mathrm{MgAl}-\mathrm{hydrotalcites}$ with a fixed $\mathrm{Mg} / \mathrm{Al}$ ratio of 4:1 were prepared through urea-precipitation by using a certain amount of $\mathrm{Mg}\left(\mathrm{NO}_{3}\right)_{2} \cdot 6 \mathrm{H}_{2} \mathrm{O}$ to $\mathrm{Al}\left(\mathrm{NO}_{3}\right)_{3} \cdot 9 \mathrm{H}_{2} \mathrm{O}$ and the urea/ $\mathrm{NO}_{3}{ }^{-}$molar ratio of 2:1 [51,52]. The resulted precipitants were calcined at $823 \mathrm{~K}$ for $8 \mathrm{~h}\left(\mathrm{~N}_{2}\right.$ atmosphere $)$ in a tube furnace to give the products, termed as $\mathrm{MgAlO}$. The modification of $\mathrm{MgAlO}$ was carried out as follows: $\mathrm{MgAlO}$ and pre-calculated ammonium persulfate were dissolved in decarbonated water $(1.0 \mathrm{~g}$ of mixture in $50 \mathrm{~mL}$ of water) for $9 \mathrm{~h}$ at room temperature with vigorous stirring, followed with the evaporation of the suspension using a rotary evaporator. The obtained solid was ground into powder and then calcined at $823 \mathrm{~K}$ for $8 \mathrm{~h}\left(\mathrm{~N}_{2}\right)$. The resulted catalyst was denoted as $\mathrm{SMgAlO}-\mathrm{y}$, where y represents the input amount of ammonium persulfate.

\subsection{Catalyst Characterization}

\subsubsection{General Tests}

X-ray diffraction (XRD) analysis was conducted on Bruker D8 Advance powder X-Ray diffractometer (Bruker, Karlsruhe, Germany) by using $\mathrm{Cu} \mathrm{K} \alpha$ radiation at $40 \mathrm{kV}$ and $200 \mathrm{~mA}$. The scan range covered from $5-80^{\circ}$ at a rate of $8^{\circ} / \mathrm{min}$. The textural parameters were obtained from $\mathrm{N}_{2}$ adsorption-desorption isotherm measured at $77 \mathrm{~K}$ on a Micromeritics ASAP 2020 surface area and porosity analyzer (Micromeritics Instrument Corp., Atlanta, GA, USA). The samples were pre-degassed at $473 \mathrm{~K}$ for $4 \mathrm{~h}$. Multipoint Brunauer-Emmett-Teller (BET) analysis method was used to calculate the specific surface area. The morphologies of catalysts were observed by scanning electron microscope (SEM), using a Hitachi S-4800 instrument (Hitachi, Tokyo, Japan). The Mg and Al contents were determined using inductively-coupled plasma (ICP) optical emission spectroscopy (OES) on a Perkin Elmer ICP-OES Optima 3000 instrument (Perkin Elmer, Waltham, MA, USA). The contents of non-metallic element were measured using an elemental analysis instrument (EA). Fourier transform-infrared spectroscopy (FT-IR) spectra were obtained using an Agilent Cary 660 spectrometer (Agilent, Palo Alto, CA, USA). Py-IR spectra were recorded on a Perkin Elmer Spectrum One FT-IR spectrometer (Perkin Elmer, Waltham, MA, USA). The solid sample was pretreated under vacuum at $423 \mathrm{~K}$ for $24 \mathrm{~h}$. Then, the solid sample (about $20 \mathrm{mg}$ ) was pressed into a self-supporting wafer of $13 \mathrm{~mm}$ diameter and treated under vacuum at $423 \mathrm{~K}$ for $2 \mathrm{~h}$. The background spectrum was recorded first after the sample was cooled to room temperature. Pyridine was introduced into the sample for 5 min, and then consequently desorbed at $423 \mathrm{~K}$. Finally, the spectrum was recorded with a $4 \mathrm{~cm}^{-1}$ resolution at the range of 1600-1400 $\mathrm{cm}^{-1}$. X-ray photoelectron spectra (XPS) were measured with a Kratos Axis HSi photoelectron spectrometer equipped with $\mathrm{Al} \mathrm{K} \alpha$ radiation ( $\mathrm{h} v=1486.6 \mathrm{eV}$ ) (Shimadzu, Kyoto, Japan). A power of $250 \mathrm{~W}$ and a pass energy of $37.5 \mathrm{eV}$ were used during the experiment. The base pressure of the chamber was higher than $3 \times 10^{-9}$ Torr. Temperature-programmed desorption of $\mathrm{CO}_{2}\left(\mathrm{CO} \mathrm{O}_{2}-\mathrm{TPD}\right)$ and $\mathrm{NH}_{3}\left(\mathrm{NH}_{3}-\mathrm{TPD}\right)$ were carried out on an AutoChem II 2920 Chemisorption equipment with a TCD and an on-line MS (Micromeritics Instrument Corp, Atlanta, GA, USA). The sample (100 mg) was reduced at $573 \mathrm{~K}$ for $2 \mathrm{~h}$ in Ar atmosphere $\left(1 / 9, v / v ; 50 \mathrm{~mL} \mathrm{~min}^{-1}\right)$, followed by purging with a high purity He flow $\left(50 \mathrm{~mL} \mathrm{~min}^{-1}\right.$ ) for $2.0 \mathrm{~h}$ at $583 \mathrm{~K}$. When the temperature decreased to $323 \mathrm{~K}, \mathrm{CO}_{2}$ (or $\mathrm{NH}_{3}$ ) was introduced until saturation, followed by purging $\mathrm{He}\left(50 \mathrm{~mL} \mathrm{~min}{ }^{-1}\right)$ for $90 \mathrm{~min}$ to remove physisorbed $\mathrm{CO}_{2}\left(\right.$ or $\left.\mathrm{NH}_{3}\right)$. Finally, the sample was heated from $323 \mathrm{~K}$ to $1023 \mathrm{~K}$ at a rate of $10 \mathrm{~K} / \mathrm{min}$, and the released $\mathrm{CO}_{2}$ (or $\left.\mathrm{NH}_{3}\right)$ was monitored by a mass spectrometer.

\subsubsection{Titration Characterization}

Basic strength of the heterogeneous acid catalyst is determined via the Hammett indicator method, where the indicators include bromothymol blue $\left(\mathrm{pK}_{\mathrm{a}}=7.2\right)$, phenolphthalein $\left(\mathrm{pK}_{\mathrm{a}}=9.3\right)$, 2,4,6-trinitroaniline $\left(\mathrm{pK}_{\mathrm{a}}=12.2\right)$, and 2,4-dinitroaniline $\left(\mathrm{pK}_{\mathrm{a}}=15.0\right)$. A total of $0.1 \mathrm{~g}$ catalyst is shaken in $5 \mathrm{~mL}$ methanol, and left for color variation or not. Color change demonstrates that the basic 
strength of the catalyst is stronger than the Hammett indicator. For the determination of soluble basicity, the catalyst was mixed with an excess amount of benzene carboxylic acid solution of known concentration. The residual benzene carboxylic acid solution concentration was determined by titration with standard $\mathrm{NaOH}$ and the amount of benzene carboxylic acid solution consumed by the catalyst was then determined.

\subsubsection{IGC Characterization}

IGC [28] was carried out to measure the acid-base interaction constants $\mathrm{K}_{\mathrm{a}}$ and $\mathrm{K}_{\mathrm{b}}$. A conventional gas chromatograph (Kechuang, GC-910, Shanghai, China) with a thermal conductivity detector was used for the measurements. The column filler was a prepared catalyst and all columns were packed with mechanical vibration, and the two ends were plugged with deactivated glass wool. The columns were pretreated in the GC system at $403 \mathrm{~K}$ overnight with a nitrogen flow rate of $20 \mathrm{~mL} \mathrm{~min}{ }^{-1}$. Measurements were carried out in the temperature range from 343 to $373 \mathrm{~K}$. High-purity nitrogen was used as the carrier gas, and flow rates were measured using a soap bubble flow meter. In order to encounter the requirement of adsorption at infinite dilution, the probes injected were in the range from $0.2-0.3 \mu \mathrm{L}$. The procedures and thermodynamic concepts which link the net retention volume of the IGC experiment with the dispersive surface free energy of the catalysts, $\gamma_{s}^{d}$, and their acid and base interaction constants, $\mathrm{K}_{\mathrm{a}}$ and $\mathrm{K}_{\mathrm{b}}$ have been fully described elsewhere. The properties of the employed probes are summarized in Table S1 (Supporting information). Tables S2-S16 list the retention time, Vn, and RTlnVn of the catalysts at various temperatures, adsorption free energy, and adsorption enthalpy of polar probes on the surface.

\subsection{Catalyst Test}

In a typical experiment, pre-calculated 1,2-propylene glycol, urea and catalyst were mixed in a $100 \mathrm{~mL}$ round-bottomed flask. The reaction was carried out at $433 \mathrm{~K}$ for $5 \mathrm{~h}$. During this period, the generated ammonia was removed by nitrogen and absorbed by dilute sulfuric acid. After the reaction, the catalyst was centrifuged from the substrate, then ultrasonically washed three times with ethanol, and finally dried at $333 \mathrm{~K}$ for the next use. The reaction products were determined using gas chromatography (GC-2014, SHIMADZU, Kyoto, Japan, country) equipped with an Rtx-1701 gas capillary column. The analysis conditions were as follows: $\mathrm{N}_{2}$ as the carrier, FID temperature of 473 $\mathrm{K}$, injection port temperature of $453 \mathrm{~K}$, and the program-controlled column temperature: initial oven temperature was kept at $353 \mathrm{~K}$ for $3 \mathrm{~min}$ and then increased with a rate of $10 \mathrm{~K} \mathrm{~min}^{-1}$ to $433 \mathrm{~K}$. The PC yield was quantitatively analyzed through an internal standard method by using acetophenone as the internal standard substance.

The conversion of PG and selectivity of PC were calculated on the basis of its weight percent using GC data as follows:

$$
\begin{gathered}
\text { Conversion }=\left(1-\frac{\text { Concentration of PG }}{\text { Concentration of original PG }}\right) \times 100 \% \\
\text { Selectivity }=\frac{\text { Concentration of PC }}{\text { Concentration of original PG } \times \text { Conversion }} \times 100 \% \\
\text { Yield }=\text { Conversion } \times \text { Selectivity } \times 100 \%
\end{gathered}
$$

\section{Conclusions}

A series of acid-base bifunctional catalysts, $\mathrm{SMgAlO}-\mathrm{y}$, were prepared using layer dioxide material magnesium aluminum oxide as supports, which were modified by different amounts of ammonium persulfate. The formed covalent $\mathrm{S}=\mathrm{O}$ bonds in the catalysts could interpenetrate surface structures, the specific surface area, as well as acid-base property of the samples. The resulting dioxides promoted the catalytic alcoholysis from urea and PG to PC with gradually increasing sulfur additives at the 
initial stage (catalysts were marked as SMgAlO-1 to 5), whereas further enhancement of sulfur species (SMgAlO-7) unexpectedly deteriorated the activity in the alcoholysis process. This volcanic variation of catalytic activity can be illustrated as the interpenetration effect leading to partial collapse of the pristine dioxide framework, which was proved by the decrease in specific surface area, followed by the coverage of the expanded specific surface acidic site.

The target catalyst SMgAlO-5 exhibited the highest $\mathrm{K}_{\mathrm{a}} / \mathrm{K}_{\mathrm{b}}$ value presented by the IGC and various characterizations. This optimal material revealed as a facile catalyst candidate in the catalytic alcoholysis to produce PC. And the target PC yield can reach $97.2 \%$ with the reaction conditions being as followed: $\mathrm{n}_{(\mathrm{PG})} / \mathrm{n}_{\text {(urea) }}=3$; mass fraction of the catalyst $=1 \%$; reaction time $=5 \mathrm{~h}$; reaction temperature $=433 \mathrm{~K}$. After five runs of the recycling test, the PC yield still maintained higher than $85 \%$.

Supplementary Materials: The following are available online at http://www.mdpi.com/2073-4344/9/5/470/s1; Figure S1. SEM of (A) SMgAlO-1; (B) SMgAlO-3; and (C) SMgAlO-7; Figure S2. N 2 adsorption and desorption isotherms (77K) for MgAlO (blue), SMgAlO-1 (black), SMgAlO-3 (green), SMgAlO-5 (red), and SMgAlO-7 (magenta); Table S1. The properties of probes; Table S2. The retention time, Vn, and RTlnVn of the MgAlO catalyst at various temperatures; Table S3. $\gamma_{\mathrm{s}}^{\mathrm{d}} / \mathrm{mJ} \cdot \mathrm{m}^{-2}$ values of the MgAlO catalyst versus temperature; Table S4. Adsorption free energy and adsorption enthalpy of polar probes on the surface of the $\mathrm{MgAlO}$ catalyst; Table S5. The retention time, Vn, and RTlnVn of SMgAlO-1 catalyst at various temperatures; Table S6. $\gamma_{\mathrm{s}}^{\mathrm{d}} / \mathrm{mJ} \cdot \mathrm{m}^{-2}$ values of SMgAlO-1 catalyst versus temperature; Table S7. Adsorption free energy and adsorption enthalpy of polar probes on the surface of SMgAlO-1 catalyst; Table S8. The retention time, Vn, and RTlnVn of the SMgAlO-3 catalyst at various temperatures; Table S9. $\gamma_{\mathrm{s}}^{\mathrm{d}} / \mathrm{mJ} \cdot \mathrm{m}^{-2}$ values of the SMgAlO-3 catalyst versus temperature; Table S10. Adsorption free energy and adsorption enthalpy of polar probes on the surface of the SMgAlO-3 catalyst; Table S11. The retention time, $\mathrm{Vn}$, and RTlnVn of SMgAlO-5 catalyst at various temperatures; Table S12. $\gamma_{\mathrm{s}}^{\mathrm{d}} / \mathrm{mJ} \cdot \mathrm{m}^{-2}$ values of $\mathrm{SMgAlO}-5$ catalyst versus temperature; Table S13. Adsorption free energy and adsorption enthalpy of polar probes on the surface of SMgAlO-5 catalyst; Table S14. The retention time, Vn, and RTlnVn of the SMgAlO-7 catalyst at various temperatures; Table S15. $\gamma_{\mathrm{s}}^{\mathrm{d}} / \mathrm{mJ} \cdot \mathrm{m}^{-2}$ values of the SMgAlO-7 catalyst versus temperature; Table S16. Adsorption free energy and adsorption enthalpy of polar probes on the surface of the SMgAlO-7 catalyst.

Author Contributions: X.R. and J.L. conceived and designed the experiments; Z.D. performed the experiments; Z.D. and W.X. analyzed the data; Z.L. and J.S. contributed reagents/materials/analysis tools; X.Z. and M.J. checked and revised the grammar writings, Z.D. and W.X. wrote the paper.

Acknowledgments: This work was supported by the National Basic Research Program of China, funded Priority Academic Program Development of Jiangsu Higher Education Institutions (PAPD), and State Key Laboratory of Materials Chemical Engineering open subject (KL14-09).

Conflicts of Interest: The authors declare no conflict of interest.

\section{References}

1. Li, H.Y.; Li, C.; Zhang, M.; Wang, K.; Xie, B. Removal of V(V) from aqueous Cr(VI)-bearing solution using anion exchange resin: Equilibrium and kinetics in batch studies. Hydrometallurgy 2016, 165, 381-389. [CrossRef]

2. An, H.L.; Ma, Y.H.; Zhao, X.Q.; Wang, Y.J. Preparation of Zn-Al oxide catalyst and its catalytic performance in propylene carbonate synthesis from urea and propylene glycol on a fixed-bed reactor. Catal. Today 2016, 264, 136-143. [CrossRef]

3. Jiang, H.-F.; Yuan, B.-Z.; Qi, C.-R. Coupling of carbon dioxide with epoxides catalyzed by amino acid hydrochloride salts. Chin. J. Chem. 2008, 26, 1305-1308. [CrossRef]

4. Ma, L.; Song, L.N.; Li, F.; Wang, H.; Liu, B.H. Preparation and properties of poly (propylene carbonate)-based waterborne polyurethane-acrylate composite emulsion. Colloid Polym. Sci. 2017, 295, 2299-2307. [CrossRef]

5. Kong, J.J.; Li, Z.L.; Cao, Z.W.; Han, C.Y.; Dong, L. The excellent gas barrier properties and unique mechanical properties of poly(propylene carbonate)/organo-montmorillonite nanocomposites. Polym. Bull. 2017, 74, 5065-5082. [CrossRef]

6. Calderon, B.A.; Sobkowicz, M.J. Evidence of compatibility and thermal stability improvement of poly(propylene carbonate) and polyoxymethylene blends. J. Appl. Polym. Sci. 2018, 135, 45823. [CrossRef]

7. Li, Q.; Zhao, N.; Wei, W.; Sun, Y. Catalytic performance of metal oxides for the synthesis of propylene carbonate from urea and 1,2-propanediol. J. Mol. Catal. a-Chemical. 2007, 270, 44-49. [CrossRef]

8. Gao, Z.W.; Wang, S.F.; Xia, C.G. Synthesis of propylene carbonate from urea and 1,2-propanediol. Chin. J. Chem. 2009, 20, 131-135. [CrossRef] 
9. Du, Z.; Chen, F.; Lin, Z.; Li, X.; Yuan, H.; Wu, Y. Effect of $\mathrm{MgO}$ on the catalytic performance of $\mathrm{MgTiO}_{3}$ in urea alcoholysis to propylene carbonate. Chem. Eng. J. 2015, 278, 79-84. [CrossRef]

10. Murugan, C.; Bajaj, H.C.; Jasra, R.V. Transesterification of propylene carbonate by methanol using $\mathrm{KF} / \mathrm{Al}_{2} \mathrm{O}_{3}$ as an efficient base catalyst. Catal. Lett. 2010, 137, 224-231. [CrossRef]

11. Li, J.; Wang, L.; Shi, F.; Liu, S.; He, Y.; Lu, L.; Ma, X.; Deng, Y. Quaternary ammonium ionic liquids as bi-functional catalysts for one-step synthesis of dimethyl carbonate from ethylene oxide, carbon dioxide and methanol. Catal. Lett. 2011, 141, 339-346. [CrossRef]

12. Huang, Y.; Wang, X.; He, X.; Yang, Y. Gel polymer electrolyte based on poly(methyl methacrylate-maleic anhydride)-poly(ethylene glycol) monomethyl ether and organophilic rectorite clay. Clay Miner. 2010, 45, 431-440. [CrossRef]

13. Da Silva, E.; Dayoub, W.; Mignani, G.; Raoul, Y.; Lemaire, M. Propylene carbonate synthesis from propylene glycol, carbon dioxide andbenzonitrile by alkali carbonate catalysts. Catal. Comm. 2012, 29, 58-62. [CrossRef]

14. Doya, M.; Ohkawa, T.; Kanbara, T.; Okamoto, A.; Kimizuka, K. A process for producing alkylene carbonates. European Patent No. EP2657214, 30 March 1994.

15. Huang, S.; Liu, S.; Li, J.; Zhao, N.; Wei, W.; Sun, Y. Modified zinc oxide for the direct synthesis of propylene carbonate from propylene glycol and carbon dioxide. Catal. Lett. 2007, 118, 290-294. [CrossRef]

16. Yu, G.L.; Chen, X.R.; Chen, C.L. Synthesis of propylene carbonate from urea and 1,2-propylene glycol over ZnO/NaY catalyst. Catal. Lett. 2009, 97, 69-75. [CrossRef]

17. Trost, B.M. The atom economy-a search for synthetic efficiency. Science 1991, 254, 1471-1477. [CrossRef]

18. Gryglewicz, S.; Oko, F.A.; Gryglewicz, G. Synthesis of modern synthetic oils based on dialkyl carbonates. Ind. Eng. Chem. Res. 2003, 42, 5007-5010. [CrossRef]

19. Meher, L.C.; Sagar, D.V.; Naik, S.N. Technical aspects of biodiesel production by transesterification-A review. Renew. Sust. Energ. Rev. 2006, 10, 248-268. [CrossRef]

20. Zhang, R.; Hua, L.; Guo, L.; Song, B.N.; Chen, J.Z.; Hou, Z.S. Calcined Mg-Al layered double hydroxide as a heterogeneous catalyst for the synthesis of urea derivatives from amines and $\mathrm{CO}_{2}$. Chin. J. Chem. 2013, 31, 381-387. [CrossRef]

21. Meloni, D.; Monaci, R.; Cutrufello, M.G.; Rombi, E.; Ferino, I. Adsorption microcalorimetry characterization of K-doped mgal mixed oxide catalysts for soybean oil transesterification synthesized by impregnation and ball milling techniques. J. Therm. Anal. Calorim. 2015, 119, 1023-1036. [CrossRef]

22. Luo, R.C.; Zhang, W.Y.; Zhou, X.T.; Ji, H.B. Tannic acid as a polyphenol material-assisted synthesis of cyclic carbonates using $\mathrm{CO}_{2}$ as a feedstock: Kinetic characteristic and mechanism studies. Chin. J. Chem 2017, 35, 659-664. [CrossRef]

23. Wang, J.; Cheng, J.; Zhou, Y.; Meng, L.; Wang, Y.; Ren, X.; Liang, J.; Jiang, M. Synergistic interactions between Ti-OOH and $\left(\mathrm{PO}_{4} \mathrm{WO}_{2}(\mathrm{O}-2)(4)\right)(3-)$ of $\mathrm{HPW} / \mathrm{Zn}$-Ti hydrotalcites: Efficient heterogeneous catalysts for the epoxidation of fatty acid methyl ester. J. Brazil. Chem. Soc. 2018, 29, 67-73. [CrossRef]

24. Perotti, G.F.; Barud, H.S.; Ribeiro, S.J.L.; Constantino, V.R.L. Bacterial cellulose as a template for preparation of hydrotalcite-like compounds. J. Brazil. Chem. Soc. 2014, 25, 1647-1655. [CrossRef]

25. Nakagaki, S.; Castro, K.A.D.F.; Ucoski, G.M.; Halma, M.; Prevot, V.; Forano, C.; Wypych, F. Anionic iron(III) porphyrin immobilized on/into exfoliated macroporous layered double hydroxides as catalyst for oxidation reactions. J. Brazil. Chem. Soc. 2014, 25, 2329-2338. [CrossRef]

26. Marcato, P.D.; Parizotto, N.V.; Martinez, D.S.T.; Paula, A.J.; Ferreira, I.R.; Melo, P.S.; Duran, N.; Alves, O.L. New hybrid material based on layered double hydroxides and biogenic silver nanoparticles: Antimicrobial activity and cytotoxic effect. J. Brazil. Chem. Soc. 2013, 24, 266-272. [CrossRef]

27. Ren, X.Q.; Hu, X.; Zhang, F.; Wang, J.E.; Liang, J.H.; Wu, W.L.; Jiang, M.; Wang, J. Synthesis of sulphur-modified bifunctional hydrotalcites and study of their surface characteristics by inverse gas chromatography. Catal. Sci. Technol. 2015, 5, 4813-4820. [CrossRef]

28. Ju, X.H.; Xiao, H.M.; Xia, Q.Y. Theoretical study on intermolecular interactions and thermodynamic properties of difluoroamine complex. Chin. J. Chem. 2003, 21, 1440-1446. [CrossRef]

29. Wang, Y.Y.; Wu, Y.T.; Wang, Y.; Dai, L.Y. Experimental and theoretical investigation of one-pot synthesis of 2-amino-4H-chromenes catalyzed by basic-functionalized ionic liquids. Chin. J. Chem. 2012, 30, 1709-1714. [CrossRef]

30. Zhou, R.Y.; Jiang, W.; Zhang, L.N.; Wang, L.; Liu, C.L. Extra copper-mediated enhancement of the DNA cleavage activity supported with wild-type $\mathrm{Cu}, \mathrm{Zn}$ superoxide dismutase. Chin. J. Chem. 2008, 26, 564-570. [CrossRef] 
31. Yasir, A.; Shukla, K.; Srivastava, V.C. Synthesis of propylene carbonate from propane-1,2-diol and urea using hydrotalcite-derived catalysts. Energ Fuel 2017, 31, 9890-9897. [CrossRef]

32. Ionescu, R.; Pavel, O.D.; Birjega, R.; Zavoianu, R.; Angelescu, E. Epoxidation of cyclohexene with $\mathrm{H}_{2} \mathrm{O}_{2}$ and acetonitrile catalyzed by $\mathrm{Mg}-\mathrm{Al}$ hydrotalcite and cobalt modified hydrotalcites. Catal. Lett. 2010, 134, 309-317. [CrossRef]

33. Du, Z.P.; Liu, L.; Yuan, H.; Xiong, J.; Zhou, B.; Wu, Y.X. Synthesis of propylene carbonate from alcoholysis of urea catalyzed by modified hydroxyapatites. Chin. J. Catal. 2010, 31, 371-373. [CrossRef]

34. Zhang, X.G.; Ke, X.B.; Zhu, H.Y. Zeolite-supported gold nanoparticles for selective photooxidation of aromatic alcohols under visible-light irradiation. Chem.-Eur. J. 2012, 18, 8048-8056. [CrossRef] [PubMed]

35. Osatiashtiani, A.; Lee, A.F.; Brown, D.R.; Melero, J.A.; Morales, G.; Wilson, K. Bifunctional $\mathrm{SO}_{4} / \mathrm{ZrO}_{2}$ catalysts for 5-hydroxymethylfufural (5-HMF) production from glucose. Catal. Sci. Tech. 2014, 4, 333-342. [CrossRef]

36. Alhassan, F.H.; Rashid, U.; Al-Qubaisi, M.S.; Rasedee, A.; Taufiq-Yap, Y.H. The effect of sulfate contents on the surface properties of iron-manganese doped sulfated zirconia catalysts. Powder Technol. 2014, 253, 809-813. [CrossRef]

37. Wang, X.S.; Ma, S.Q.; Sun, D.F.; Parkin, S.; Zhou, H.C. A mesoporous metal-organic framework with permanent porosity. J. Am. Chem. Soc. 2006, 128, 16474-16475. [CrossRef]

38. Zhou, H.R.; Li, X.G.; Ma, J.; Dong, C.F.; Huang, Y.Z. Dependence of the corrosion behavior of aluminum alloy 7075 on the thin electrolyte layers. Sci. Eng. B-Adv. 2009, 162, 1-8. [CrossRef]

39. Ishii, D.; Tatsumi, D.; Matsumoto, T. Effect of aluminum sulfate on dispersion state of sodium carboxymethylcellulose in aqueous solution. Nihon Reoroji Gakk. 2012, 40, 267-272. [CrossRef]

40. Ye, X.; Jiang, Z.; Li, L.; Xie, Z.-H. In-situ growth of nial-layered double hydroxide on AZ31 Mg alloy towards enhanced corrosion protection. Nanomaterials 2018, 8, 411-420. [CrossRef]

41. Wang, X.-F.; Xiong, S.-M. Oxidation behavior of molten magnesium in atmospheres containing $\mathrm{SO}_{2}$ and air in a sealed furnace. Corros. Sci. 2013, 66, 300-307. [CrossRef]

42. Delgado, M.G.; Garcia-Galvan, F.R.; Llorente, I.; Perez, P.; Adeva, P.; Feliu, S., Jr. Influence of aluminium enrichment in the near-surface region of commercial twin-roll cast AZ31 alloys on their corrosion behaviour. Corros. Sci. 2017, 123, 182-196. [CrossRef]

43. Shen, L.J.; Zheng, X.H.; Lei, G.C.; Li, X.; Cao, Y.N.; Jiang, L.L. Hierarchically porous $\gamma-\mathrm{Al}_{2} \mathrm{O}_{3}$ nanosheets: Facile template-free preparation and reaction mechanism for $\mathrm{H}_{2} \mathrm{~S}$ selective oxidation. Chem. Eng. J. 2018, 346, 238-248. [CrossRef]

44. Stephan, D.W.; Erker, G. Frustrated lewis pairs: Metal-free hydrogen activation and more. Angew. Chem.-Int. Edit. 2010, 49, 46-76. [CrossRef]

45. Zhang, T.T.; Zhang, B.S.; Li, L.; Zhao, N.; Xiao, F.K. Zn-Mg mixed oxide as high-efficiency catalyst for the synthesis of propylene carbonate by urea alcoholysis. Catal. Commun. 2015, 66, 38-41. [CrossRef]

46. Zhao, X.Q.; Zhang, Y.; Wang, Y.J. Synthesis of propylene carbonate from urea and 1,2-propylene glycol over a zinc acetate catalyst. Ind. Eng. Chem. Res. 2004, 43, 4038-4042. [CrossRef]

47. Jung, S.M.; Grange, P. Evidence of correlation between electronic density and surface acidity of sulfated $\mathrm{TiO}_{2}$. Catal. Lett. 2001, 76, 27-30. [CrossRef]

48. Kost, T.; Sigalov, M.; Goldberg, I.; Ben-Asuly, A.; Lemcoff, N.G. Latent sulfur chelated ruthenium catalysts: Steric acceleration effects on olefin metathesis. J. Organomet. Chem. 2008, 693, 2200-2203. [CrossRef]

49. Wang, S.P.; Shi, Y.; Ma, X.B. Effect of sulfate modification on structure properties, surface acidity, and transesterification catalytic performance of titanium-submitted mesoporous molecular sieve. Ind. Eng. Chem. Res. 2012, 51, 5737-5742. [CrossRef]

50. Fugel, M.; Hesse, M.F.; Pal, R.; Beckmann, J.; Jayatilaka, D.; Turner, M.J.; Karton, A.; Bultinck, P.; Chandler, G.S.; Grabowsky, S. Covalency and ionicity do not oppose each other-relationship between Si-O bond character and basicity of siloxanes. Chem.-Eur. J. 2018, 24, 15275-15286. [CrossRef]

51. Rao, M.M.; Reddy, B.R.; Jayalakshmi, M.; Jaya, V.S.; Sridhar, B. Hydrothermal synthesis of Mg-Al hydrotalcites by urea hydrolysis. Mater. Res. Bull. 2005, 40, 347-359. [CrossRef]

52. Costantino, U.; Marmottini, F.; Nocchetti, M.; Vivani, R. New synthetic routes to hydrotalcite-like compounds - characterisation and properties of the obtained materials. Eur. J. Inorg. Chem. 1998, 1439-1446. [CrossRef]

(C) 2019 by the authors. Licensee MDPI, Basel, Switzerland. This article is an open access article distributed under the terms and conditions of the Creative Commons Attribution (CC BY) license (http://creativecommons.org/licenses/by/4.0/). 